\title{
Kampüs Alanlarında Meydan Tasarımı: Kilis 7 Aralık Üniversitesi Örneği
}

\author{
Saliha TAŞÇIOĞLU ${ }^{1}$, Ahmet Salih GÜNAYDIN ${ }^{1}$, Murat YÜCEKAYA ${ }^{2}$ \\ ${ }^{1}$ Kilis 7 Aralık Üniversitesi, Teknik Bilimler MYO, Park ve Bahçe Bitkileri Bölümü,79000, KİLíS \\ ${ }^{2}$ Nevşehir Hacı Bektaş Veli Üniversitesi, Mühendislik - Mimarlık Fakültesi, Peyzaj Mimarlığı Bölümü,50300, \\ NEVŞEHIR
}

\section{Öz}

Meydanlar insanların bir araya gelerek sosyal aktivitelerde bulunduğu ve kentin genel karakterine uygun olarak şekillenen, belirli sınırlar ile çevrelenmiş mekânlar olarak ifade edilebilir. Günümüzde meydanların, ticari, kültürel ve rekreasyonel amaçlı kullanımları oldukça yaygındır. Özelikle gençlerin bir araya geldiği, sosyal ilişkiler kurduğu, fizyolojik ihtiyaçlarını karşıladığı, kişisel gelişime ve sosyalleşmeye yönelik kazanımları elde ettiği üniversite kampüsünde yer alan meydan karakteri taşıyan mekânlar oldukça önemlidir. Kilis 7 Aralık Üniversitesi 2007 itibariyle kurulmuş ve fiziksel gelişimini sürdürmektedir. Kampüs yapılanması sonrası sosyal etkinliklere de ev sahipliği yapabilecek bir mekân olarak meydan peyzaj tasarım projesi oluşturulmasına ihtiyaç duyulmuştur. $\mathrm{Bu}$ ihtiyaç doğrultusunda yapılan proje ile mekanın sosyal ve kültürel etkinliklerin gerçekleştirilebilmesine izin vermesinin yanı sıra günlük kullanıma da firsat veren bir yaklaşım içerisinde olmasına önem gösterilmiștir. Söz konusu proje üniversite yönetimi tarafından uygulanmış ve üniversite kullanıcıları tarafından sıklıkla tercih edilen bir mekân haline gelmiştir. Bu çalışmanın amacı Kilis 7 Aralık Üniversitesi özelinde gerçekleştirilen kampüs meydan tasarımını proje ve uygulama aşamalarıyla birlikte incelemektir. Bu bağlamda yapılan çalışmanın kampüs meydanlarının tasarımına ve kullanımına yönelik önemli ipuçları verme niteliğinde olacağı düşünülmektedir. Böylelikle yeni yapılacak olan benzer projelere kurgusal bağlamda katkılarda bulunabilecektir.

Anahtar Kelimeler: Meydan, kampüs, peyzaj tasarım, Kilis

\section{Kilis 7 Aralık University Central Campus Square Design and Implementation Practice}

\begin{abstract}
Squares are defined as spaces which are shaped according to the city's character and are delimited by certain borders in which people come together for social activities. Nowadays squares have prevalent usages in terms of commercial, cultural and recreational purposes. Especially, the places in the university campus where young people come together, establish social relations, meet their physiological needs, and benefit for their development and socialization are quite important. Kilis 7 Aralık University is established in 2007 and its physical growth is still in process. After university campus structuring was adopted, there was a need to create a square landscape design project to host social activities. In this respect, that social and cultural activities can be realized as well as utilization for daily activities was an issue taken quite seriously. The project has been applied by the university administration and the campus has become a preferred place for university users. The aim of this study is to examine the campus square design which was realized in Kilis 7 Aralık University with the project and application stages. In this context, the study is thought to provide important clues for the design and use of campus squares. In this way, it will be able to contribute to the fictional context of new similar projects.
\end{abstract}

Keywords:: Square, campus, landscape design, Kilis 


\section{Giriş}

Mekân, bir kişi veya gurubun yeri olarak tanımlanmasının yanı sıra, bileşen ve öğeleri aracılı̆̆ıyla sınırlayıcı, belirleyici, yönlendirici, odaklayıcı, süreklilik sağlayıcı, anlam taşıyıcı, birleştirici, ayırıcı roller üstlenmektedir (Gür,1996). Kentsel mekân ise sınırlanan bir boşluğu ve sınırlayan öğelerin oluşturdukları bir olguyu ifade etmektedir (Öksüz, 2004). Bu bağlamda Krier, (1979) meydanları, sınırları yapı grupları ile tanımlanmış, insanoğlunun kentsel alan kullanımlarını ilk olarak keşfettiği mekânlar olabileceğini belirtmektedir.

Kamusal bir mekân olarak ifade edilen meydanlar kentin kültür, inanç, gelenek ve görenekleri doğrultusunda şekillenmiştir. Farklı işlev ve biçimlenme gösterebildikleri gibi, insanların bir araya gelerek sosyalleştikleri alanlardır. Bir meydanın canlılığı ve görsel çekiciliği açısından işlevi hayati önem taşımaktadır (Moughtin, 2003). Bunun yanı sıra meydanın büyüklüğü ile kullanıcı sayısı arasındaki oran da önemlidir. Vitruvius (2005), forumların boyutu ile ilgili "orada yaşayan nüfusla orantılı olmalı, ne kullanılamayacak kadar küçük ne de içerisinde kullanıcı varken çöl gibi atıl görünecek büyüklükte olmalıdır" demektedir. Binalar arasında yer alan ve çevre ortamların ek yeri olarak çalışan açık alanlar, farklı yerleri ve unsurları entegre ederek ve düzenleyerek bir kampüs içinde yön duygusu sağlar; ayrıca çekici çevreleri dahil ederek ve görsel sürprizlerle birlikte estetik bir his sağlayabilirler. (Payne, 2009; Lau et all,2014 )

Meydanları biçimsel olarak değerlendiren Krier (1979), kent meydanlarının temelde üç ana biçimden (kare, daire ve üçgen) türediğini ve bu temel biçimlerin farklı kullanımları ile mekânların şekillendiğini söylemektedir. Bu şekilde biçimlenen meydanların tamamen ya da kısmen binalarla çevrili olması, kesişen sokakların sayısı ve pozisyonu, mekânın "kapalı" veya "açık" terimleriyle tanımlanmasını sağlamaktadır (Krier, 1979).

Sitte (1983)'e göre açık mekânın merkez noktası tasarım ve işlevsel açıdan açık olmalıdır ve heykel, çeşme gibi donatıların mekân kenarına yerleştirilmesi daha uygundur. Açık mekân kapalı bir izlenime sahip olmalıdır, bu anlamda kemer ve sütunlar kullanılabilmelidir, dar alanda yüksek binalı derin açık mekân, geniş alanda alçak ön cepheli geniş açık mekân tasarlanmalıdır. Açık mekânın tasarım ilkesi olarak düzensizlik tercih edilebilmelidir. Bunun yanında, farklı büyüklükteki kesişen yollar, bağlantılar ile hareketlilik sağlanabilir (İnceoğlu,2007).

Bir düğüm fonksiyonu üstlenen kent meydanları, insanların bir araya gelmelerini sağlamaktadır. Kent yaşantısında süregelen küçük toplantılar, mitingler, törenler, festivaller, karnavallar vb. gibi aktiviteler hep meydanlarda gerçekleştirilmektedir (Kamberov,2016). Meydan mekânında sunulan satış birimleri, sergi alanları, konser ve gösteri platformları, çeşitli seyir ve oturma mekânları gibi zengin aktivite çeşitleriyle, mekânın her yönüyle kullanılabilirliği, yaşayan bir mekân olması sağlanır. Aktivitelerin, meydanla bağlantılı yaya aksları ve meydanın giriş ve çıkışları yakınında yer almasıyla, insanların gelme-gitme faaliyetlerini, kendilerini daha çok rahatlatacak faaliyetlere doğru kaydırma şansı olacaktır. Kullanıcı gurubu için; mekânda iyi vakit geçirebilme, görsel kalite, konfor, fonksiyonların çeşitliliği, boş zamanlarını değerlendirebilecekleri ve sıkılmayacakları aktivitelerden oluşan alanların yer alması önemlidir (Alexander, 1977; Kamberov,2016).

Bu çalışma ile Kilis 7 Aralık Üniversitesi Merkez Kampüsü'nde sosyal etkinliklere ve öğrencilerin kullanımına ev sahipliği yapabilecek bir meydan tasarım çalışması amaçlanmıştır. Bu çerçevede konuyla ilgili kavramlar açıklanmış, mekanda ne tür donatılar kullanılması gerektiği ve bu donatıların kullanım olanakları araştırılmış, alan ile ilgili analiz çalışmaları yapılmıştır. Analiz çalışmaları ve kullanıcı ihtiyaçlarına yönelik mekân belirlemeleri yapılarak, meydan tasarımı gerçekleştirilmiş ve uygulanmıştır. Sonuçta; kampüs meydan tasarımı konusunda çalışacak tasarımcılara ışık tutacak öneriler ile birlikte uygulama çalışmaları konusunda bilgiler verilmiştir.

\section{Materyal ve Metot}

\subsection{Materyal}

Yüzölçümü $1.521 \mathrm{~km} 2$ olan Kilis, $36^{\circ} 37^{\prime} 54.5^{\prime \prime} \mathrm{N} 37^{\circ} 02^{\prime} 17.6^{\prime \prime} \mathrm{N}$ Kuzey enlemleri ile $36^{\circ} 42^{\prime} 36.6^{\prime \prime E} 37^{\circ} 34^{\prime}$ 07.0"E Doğu boylamları arasında yer alır. Akdeniz ile Güneydoğu Anadolu iklimi arasında geçiş bölgesinde bulunan kent, kuzeyinde Gaziantep, batısında Hatay ve güneyinde ise Suriye ile çevrilidir (Şekil 1). Kentte ortalama sıcaklık $17.2^{\circ} \mathrm{C}$ iken yıllık yağış miktarı $492 \mathrm{~mm}$ 'dir.

Çalışmanın ana materyalini Kilis 7 Aralık Üniversitesi Merkez Kampüsü oluşturmaktadır. Merkeze uzaklığı 2 km olan kampüs içerisinde yaklaşı 6700 öğrenci öğrenim görmektedir. Kampüs toplamda $258.000 \mathrm{~m}^{2}$ alana sahiptir. Bu alanın $50.152 \mathrm{~m}^{2}$ si bina oturum alanıdır. Toplamda yaklaşık $52.000 \mathrm{~m}^{2}$ yeşil alan bulunmaktadır. 


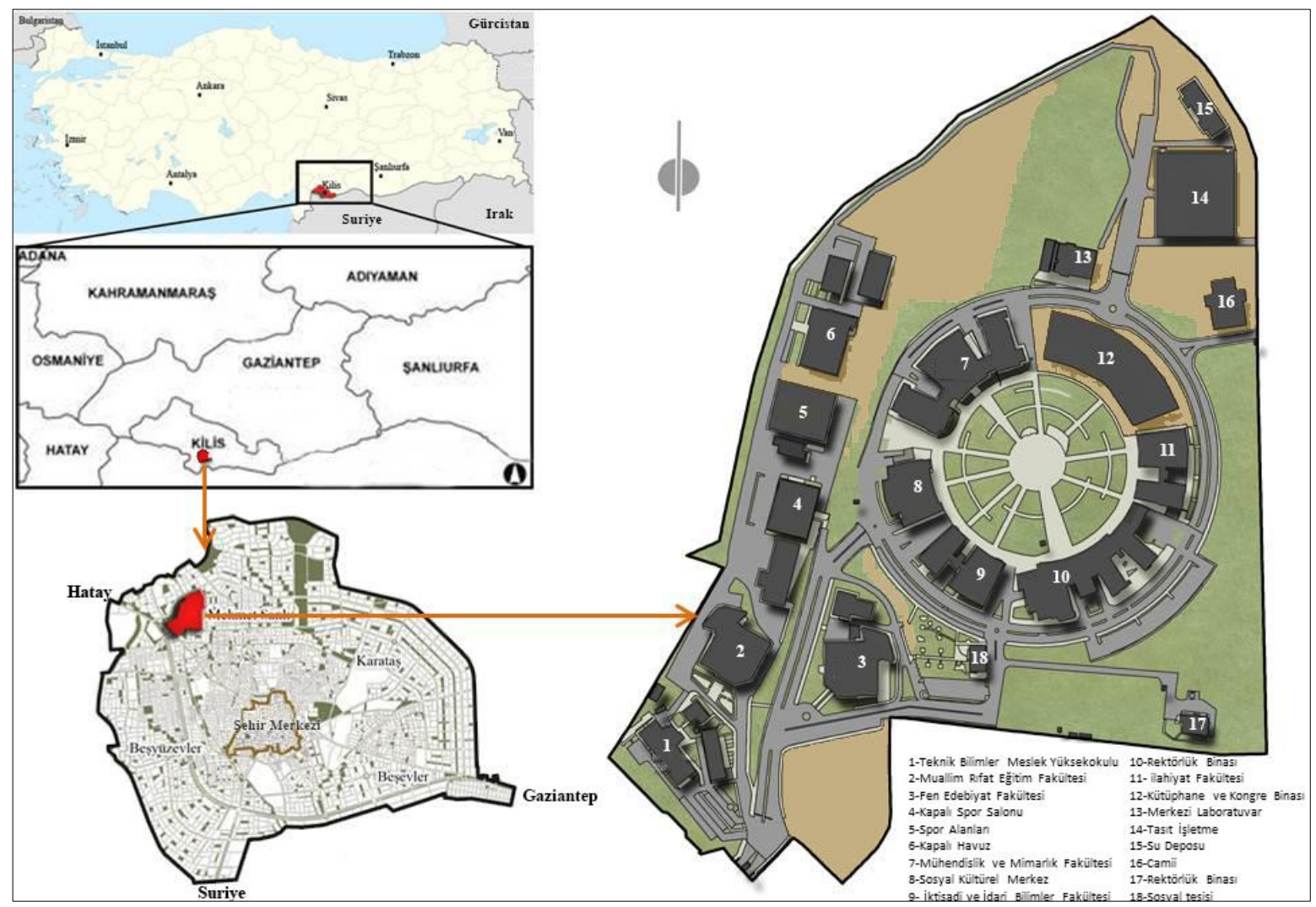

Şekil 1. Çalışma alanı konumu

\subsection{Metot}

Çalışma merkez kampüs içerisinde bir meydan ihtiyacının ortaya çıkması ve rektörlük kararıyla bu konuda talebin oluşturulmasıyla başlamıştır. Çalışmanın yöntemi planlama ve alan analizi, peyzaj tasarım projesi ve uygulama aşaması olmak üzere üç başlıktan oluşmaktadır.

Planlama ve alan analizi aşamasında kullanıcı ihtiyaçları ve gerekli araştırmalar yapılarak tasarım yaklaşımı belirlenmeye çalışılmıştır. Konu ile ilgili yazılı ve görsel kaynaklar araştııılmış, gerekli bilgi ve dokümanlar doğrultusunda veriler değerlendirilmiştir.

Peyzaj tasarım projesi aşamasında, belirlenen ihtiyaç ve gereklilikler kapsamında tasarım projesi oluşturulmuştur. Bu doğrultuda yapılan çalışma ile sosyal ve kültürel etkinliklerin gerçekleştirilebilmesine izin vermesinin yanı sıra günlük kullanıma da firsat veren bir yaklaşım içerisinde olmasına önem verilmiştir. Belirlenen ihtiyaçlar doğrultusunda 3 adet taslak proje oluşturulmuş ve rektörlük birimine sunulmuştur. Yapılan değerlendirmeler sonucunda belirlenen proje kesinleştirilmiş ve detaylandırılmıştır.

Son aşamada, detaylandırılan proje bitkisel ve yapısal olmak üzere iki ayrı bölümde ele alınmıştır. Tasarım kapsamında önerilen etkinlik alanları, donatılar ve kullanılacak bitkiler belirlenerek son aşama tamamlanmıştır. Proje 2011 yılı içerisinde oluşturulmuş ve uygulaması 2013 yılında tamamlanmıştır. Çalışma süresince öneri projeler hazırlanmış ve kesinleşen proje doğrultusunda, uygulama projesi ve detaylar oluşturulmuştur. Tasarım aşamasında Autocad 2007 ile sunum ve görselleştirme aşamasında Photoshop CS2 yazılımlarından yararlanılmıştır.

\section{Bulgular ve Tartışma}

\subsection{Planlama ve Alan Analizi}

Tasarımı yapılan alan toplam yaklaşı $22.550 \mathrm{~m}^{2}$ çevresini saran yapı bütünü ise $17.267 \mathrm{~m}^{2}$ dir. Bu aşamada alan ile ilgili eksikler ve ihtiyaçların yanı sıra, iklimsel faktörler, güneş, rüzgar, manzara, drenaj, yapı ile bağlantılar, toprak yapısı, bitki varlığı belirlenmiştir. Alan kampüs kurulmadan önce çöp depolama alanı olarak kullanıldığı için içerisinde herhangi bir bitki bulunmamaktadır. Toprak yapısının iyi olmaması sebebiyle 
alandaki toprak büyük ölçüde değiştirilerek ilaveler yapılmış ve bu doğrultuda tesviye çalışması tamamlanmıştır. Alanın çevresini saran yapılar idari ve akademik birimlerden oluşmaktadır.

$\mathrm{Bu}$ doğal ve yapay verilerin tespitinden sonra kullanıcı kapasitesini belirlemek için öğrenci, idari ve akademik personel sayısı tespit edilmiştir. Öğrenci İşleri ve Personel Dairesi Başkanlığı verilerine göre Üniversite bünyesinde 2011 yılında toplam 4425 öğrenci, 75 idari, 116 Akademik personel yer almaktadır. Merkez kampüste ise 4157 öğrenci öğrenim görmektedir. Sonraki yıllarda kampüs yapılanmasının tamamlanmasıyla birlikte, kampüsün tam kullanım kapasitesi doğrultusunda, kullanıcı sayısı ortalama olarak 15000 kişi hesaplanmıştır.

\subsection{Peyzaj Tasarım Projesi}

\subsubsection{Yapısal Tasarım}

Alana ait halihazır harita doğrultusunda etkinlik alanları belirlenerek, aktif kullanıma uygun ve tercih edilen bir düzenleme yapmak öncelikli hedef olarak belirlenmiştir. Mekânsal bütünlüğü sağlayacak şekilde tasarlanan meydan farklı aktiviteler içerecek şekilde planlanmaya çalışılmıştır. $\mathrm{Bu}$ doğrultuda belirlenen kullanıcı ihtiyaçlarına yönelik olarak sosyal etkinlikler düzenlenmesi amacıyla merkez alan dairesel formda oluşturulmuştur. Sistem kurgulanırken bu merkez odak noktasına alınmıştır. Çalışmanın ilk eskiz aşaması şekil 2'de, yapısal peyzaj tasarımın son hali ise şekil 3'de verilmiştir

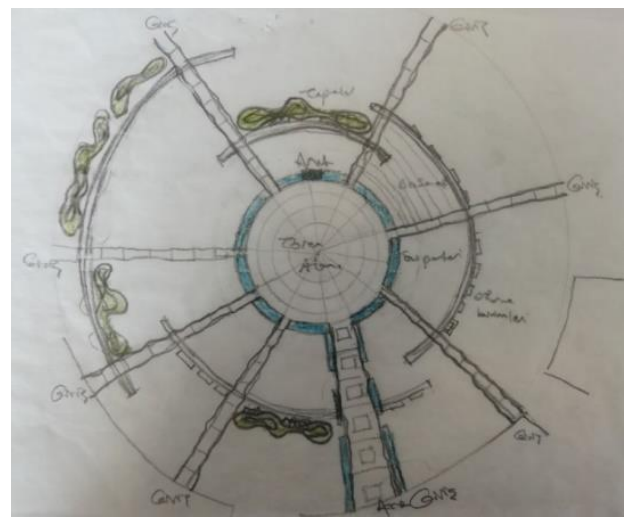

Şekil 2. İlk eskiz çalışması

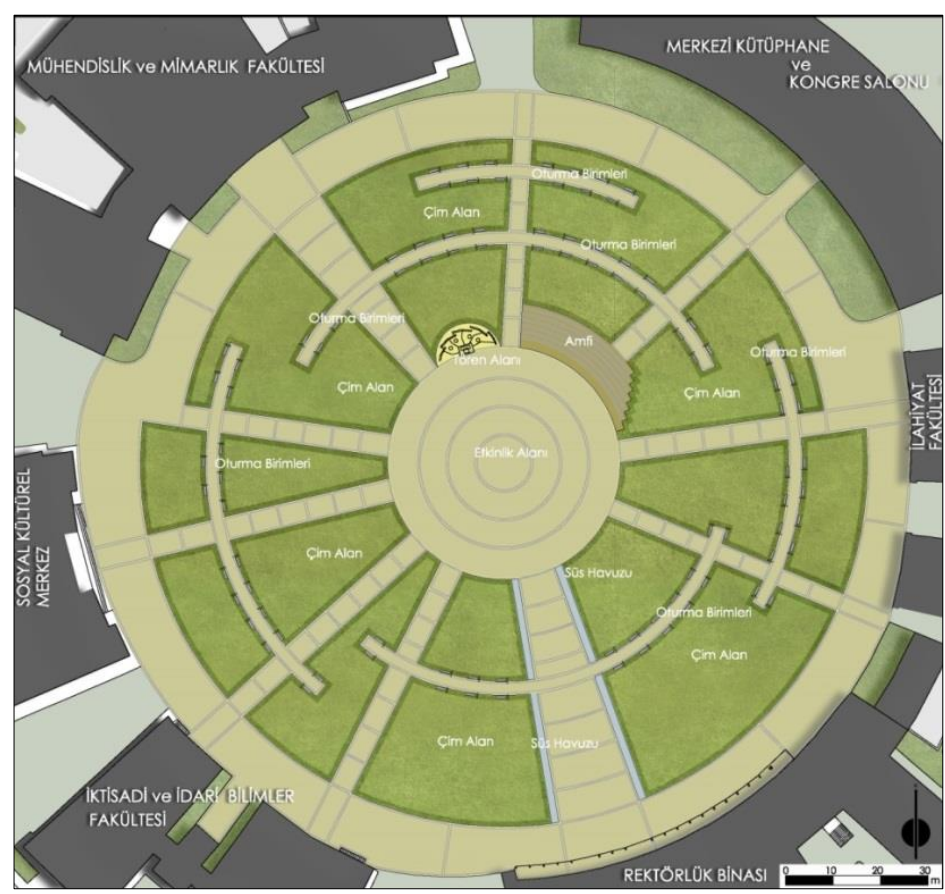

Şekil 3. Yapısal peyzaj projesi 
a)Etkinlik Alanı: Tasarımda alanın dairesel formda olması ve çevresinin yapılar ile çevrili olması sebebiyle ona uyumlu olarak ışınsal yollarla bölünen bir mekân kurgusu üzerinden hareket edilmiştir. Merkezden çıkan bu 1şınsal yollar yapılara bağlanmaktadır. Böylelikle, herhangi bir bölgeden mekâna giriş yapan kullanıcılar merkezde yer alan dairesel formlu etkinlik alanına rahatlıkla ulaşmaktadır. Ders dönemi içerisinde öğrenci yoğunluklu kullanılan alan bahar şenlikleri ile akademik açılış dönemlerinde en yüksek kullanıcı yoğunluğuna sahip olacak şekilde planlanmıştır. Meydan konser, kermes, açılış töreni, bahar şenlikleri vb. birçok etkinliğinin yapılmasına olanak tanımaktadır (Şekil 4)
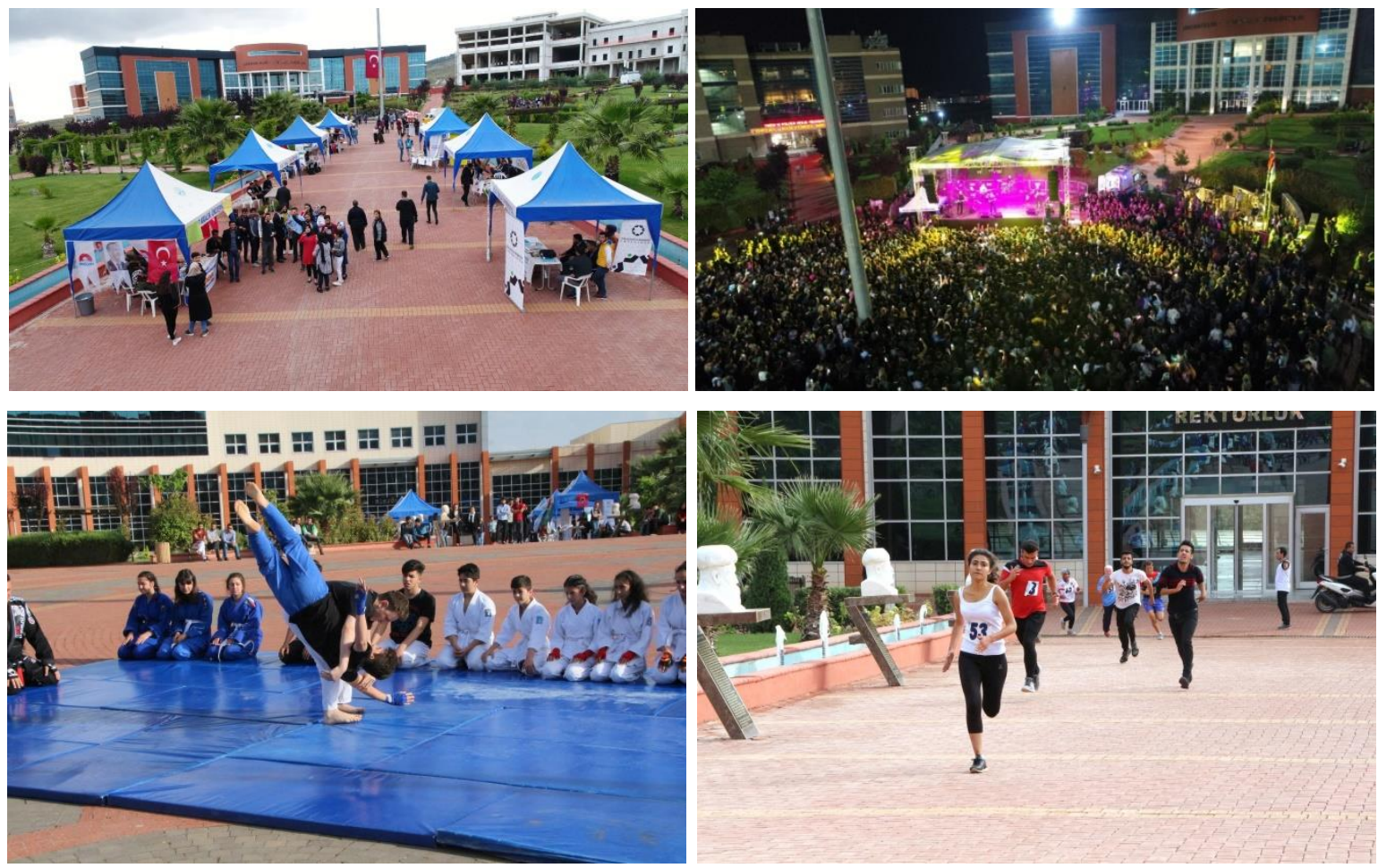

Şekil 4. Meydanda düzenlenen bazı etkinlikler

b)Su Öğesi: Rektörlük binası önünden ilerleyen aks protokol yolu olarak daha geniş tasarlanmış ve iki tarafı da süs havuzuyla desteklenmiştir (Şekil 5). Ayrıca etkinlik alanı çevresi de aynı şekilde havuzla çevrili olarak tasarlanmış ancak uygulama aşamasında iptal edilmiştir.
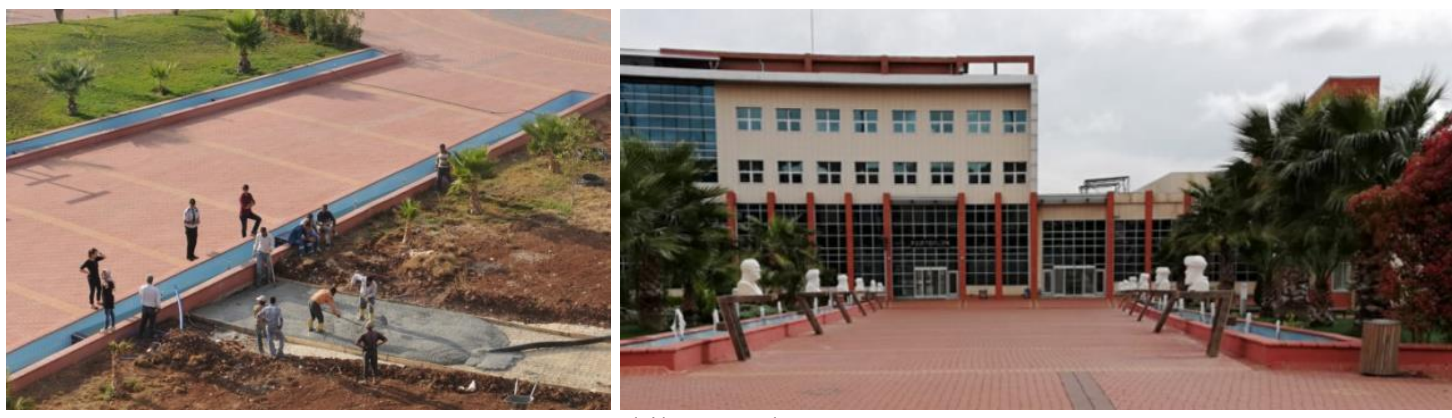

Şekil 5. Süs havuzu

c)Oturma Birimleri: Tasarımda kullanıcıların merkezde yer alan etkinlik alanını daha rahat izleyebilmeleri için bu alana hakim bir şekilde arazi eğiminden de faydalanılarak amfi tasarlanmıştır. Amfi tasarımı yapılırken, daha çok sosyal etkinliklerde ve törenlerde kullanımı göz önünde bulundurulmuş buna ek olarak; günlük kullanıma izin verecek nitelikte olmasına da özen gösterilmiştir.

Oturma alanı olarak belirlenen alanlar ise ışınsal yollar ile merkezden farklı uzaklıklarda kesişen yürüyüş yolları üzerinde oluşturulmuştur. Bu alanlarda tasarlanan oturma birimleri, bitki kasaları ile desteklenmiş ve aynı zamanda gölge oluşturacak şekilde tasarlanmıştır. Çevreye uyumu ve doğal görüntüsü nedeniyle ahşap malzeme seçilmiştir. Yürüyüş yolu aksı vurgu oluşturacak şekilde arkadlar ile desteklenmiş ve sarılıcı türler ile gölge oluşumuna katkı sağlanmıştır (Şekil 6). 

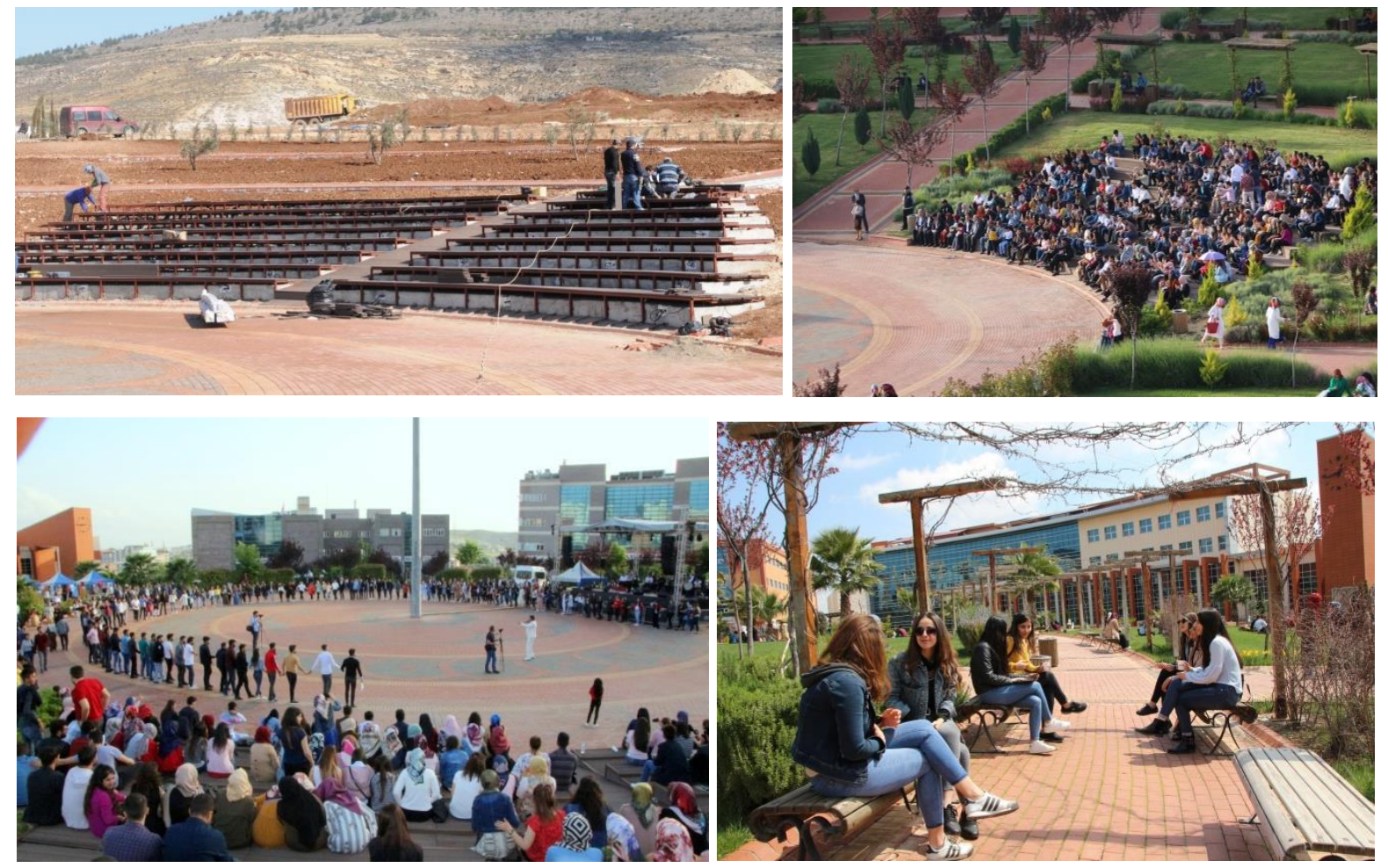

Şekil 6. Oturma birimleri

d)Aydınlatma: Altunkasa (2011) aydınlatmayı belirli bir çevre veya bu çevre içerisinde yer alan objelerin algılanma biçimini belirleyecek şekilde yapılan ışık uygulaması olarak ifade etmektedir.

Aydınlatma projesi peyzaj tasarım çalışmasında belirlenen genel sisteme uygun olarak oluşturulmuştur. Etkinlik alanına ulaşan ışınsal yolları vurgulayacak şekilde alçak aydınlatma elemanları kullanılmıştır. Yürüyüş yolları ve oturma birimlerini destekleyen aydınlatmalar ve amfiyi daha belirgin hale getirecek şekilde spot aydınlatmalar tercih edilmiştir (Şekil 7).
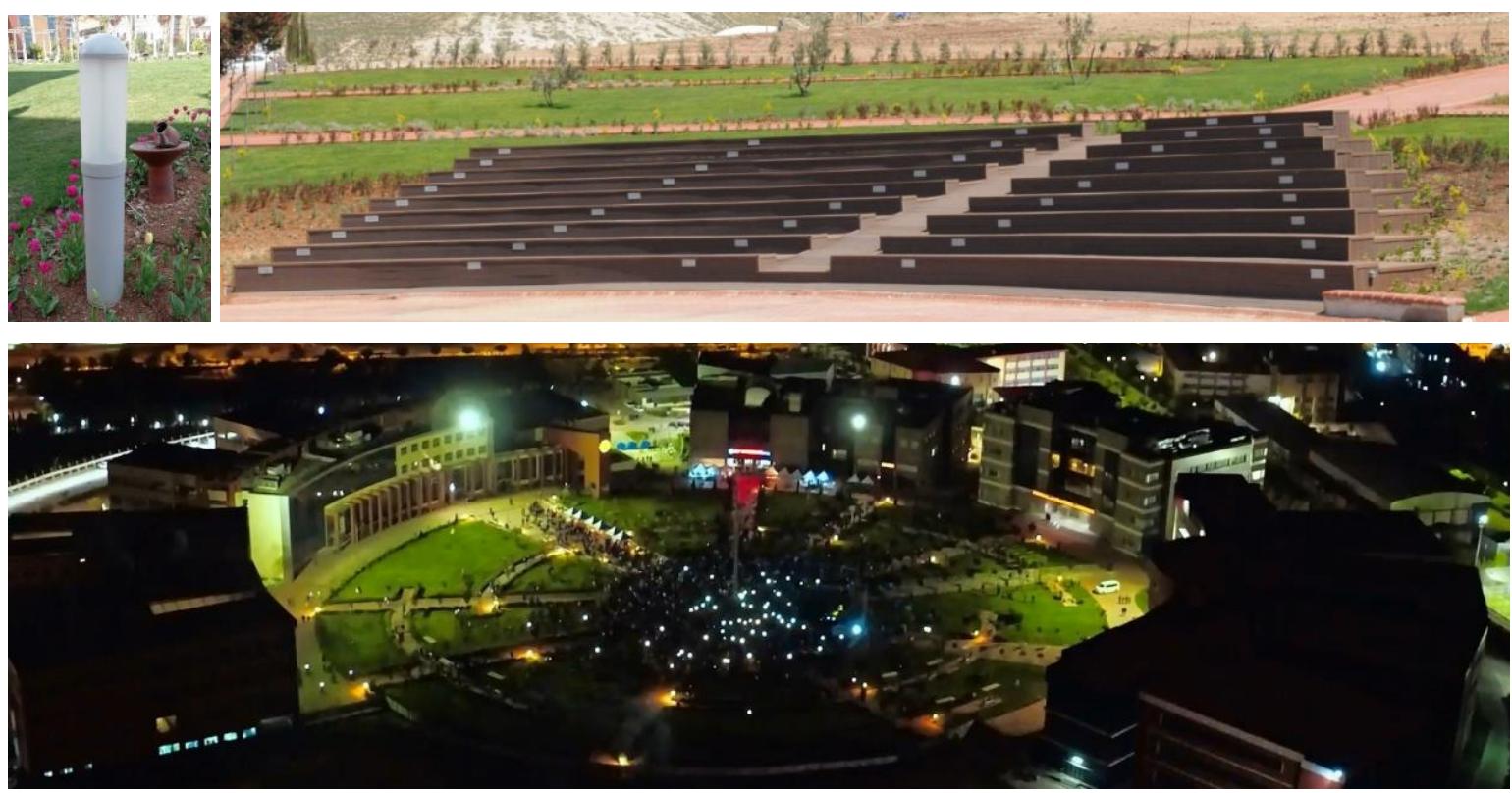

Şekil 7. Aydınlatma birimleri

e)Diğer Donatılar: Tören alanı olarak da kullanılabilmesi amacıyla Rektörlük binasına bakacak şekilde bir heykel düzenlemesi yerleştirilmesine karar verilmiştir. Alanda öğrencilerin dinlenmesine imkan veren oturma birimleri ve amfi basamakları, görsel ve fiziksel olarak rahatlatma etkisi olan süs havuzları oluşturulması uygun 
bulunmuştur. Çöp kutusu, heykel ve arkad tasarımları Şekil 8'de verilmiştir.
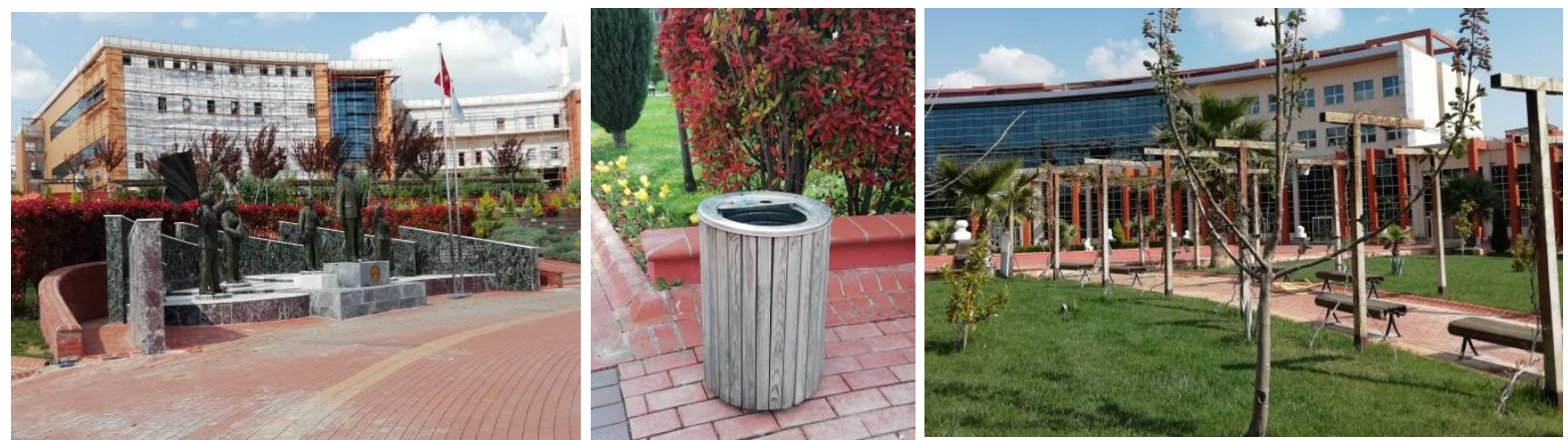

Şekil 8. Çöp kutusu, havuz, heykel ve arkad detayları

\subsubsection{Bitkisel Tasarım}

Yapısal peyzaj projesinin kesinleşmesinden sonra bitkisel tasarım çalışması için türlerin tespiti yapılmış ve kullanılabilecek bitki türleri belirlenmiştir. Ölçü, biçim, renk ve doku özellikleri doğrultusunda belirlenen bitkiler tasarımı vurgulayacak ve meydan içerisinde ihtiyaç duyulan sınırlama, yönlendirme gibi işlevleri de sağlamaktadır. Özellikle baharın gelişiyle büyük ölçüde çiçek etkisi ile vurgu yaratan, renk geçişleri sağlayan, gölge etkisi olan, sararma, kızarma gibi özellikleri bulunan türlerin seçilmesine öncelik verilmiştir (Şekil 9).
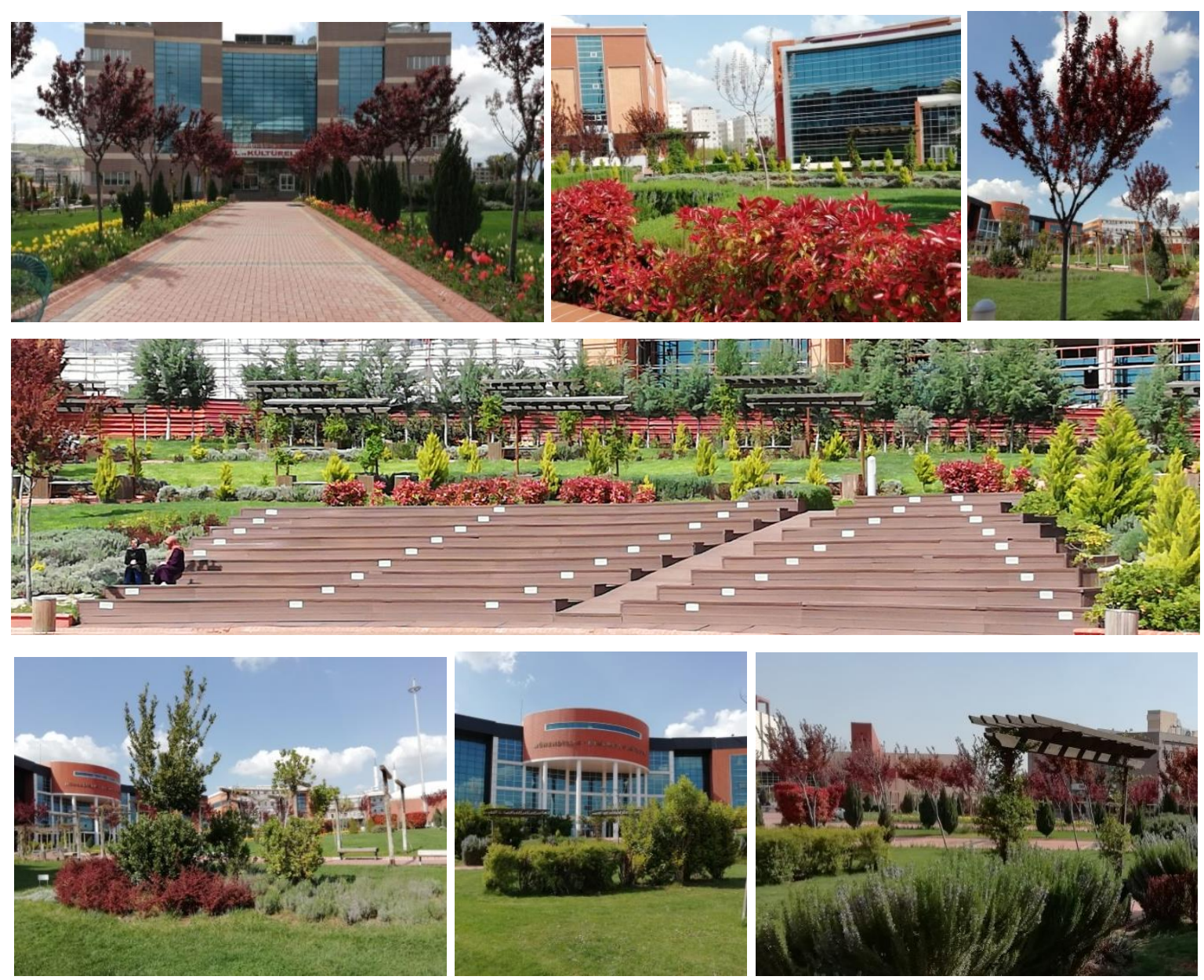

Şekil 9. Bitkisel düzenlemeler

Suyun azlığı ve buharlaşmanın fazla olması sebebiyle su ihtiyacı olarak kanaatkar bitkilerin seçilmesi ile bakım masraflarının azaltılması düşünülmüştür. Bitkisel tasarım yapılırken alanın dört mevsim boyunca yeşil ve canlı bir görünüm sergilemesine özen gösterilmiştir. Örneğin; süs eriklerinin baharın başında çiçeklenmesi ile başlayan süreç, yaz aylarında diğer çiçekli ve kokulu bitkilerin kazandırdığı görünüm, sonbaharda amerikan 
sarmaşıklarının kızarmasıyla devam etmekte, kışın yaprağını dökmeyen limoni serviler, Lawson yalancı servi ve defneler ile kış aylarında da alan tamamen çıplak bir görünümden kurtulmaktadır.

İl genelinde çok fazla kullanılmayan ancak bölgeye uyum sağlayabileceği düşünülen Lavandula officinalis, Rosmarinus officinalis, Santolina spp., Gaura spp, Pittosporum tobira'Nana', Viburnum opulus, Photinia fraseri, Chaenomeles japonica gibi türler bu anlamda katkı sağlayacağı düşünülerek dahil edilmiştir. Bu bitkisel tasarım projesine göre kullanılan ağaç ve ağaççılar, çalılar, yer örtücü ve mevsimlikler ile sarılıcı bitki türleri aşağıda belirtilmektedir (Şekil 10).

Ăgaç ve Ağaçcıklar: Albizia julibrissin (Gülibrişim), Catalpa bignonioides (Katalpa), Chamaecyparis lawsoniana "Elwoodi" (Lawson yalanc1 servisi), Cupressus macrocarpa "Goldcrest" (Limoni servi), Cupressocyparis leylandii (Leylandi), Laurus nobilis (Defne), Prunus cerasifera "Pissardii nigra” (K1rmız1 yapraklı süs eriği), Phoenix dactylifera (Hurma), Thuja orientalis (Doğu mazısı), Tilia tomentosa (Ihlamur), Washingtonia robusta (Palmiye)

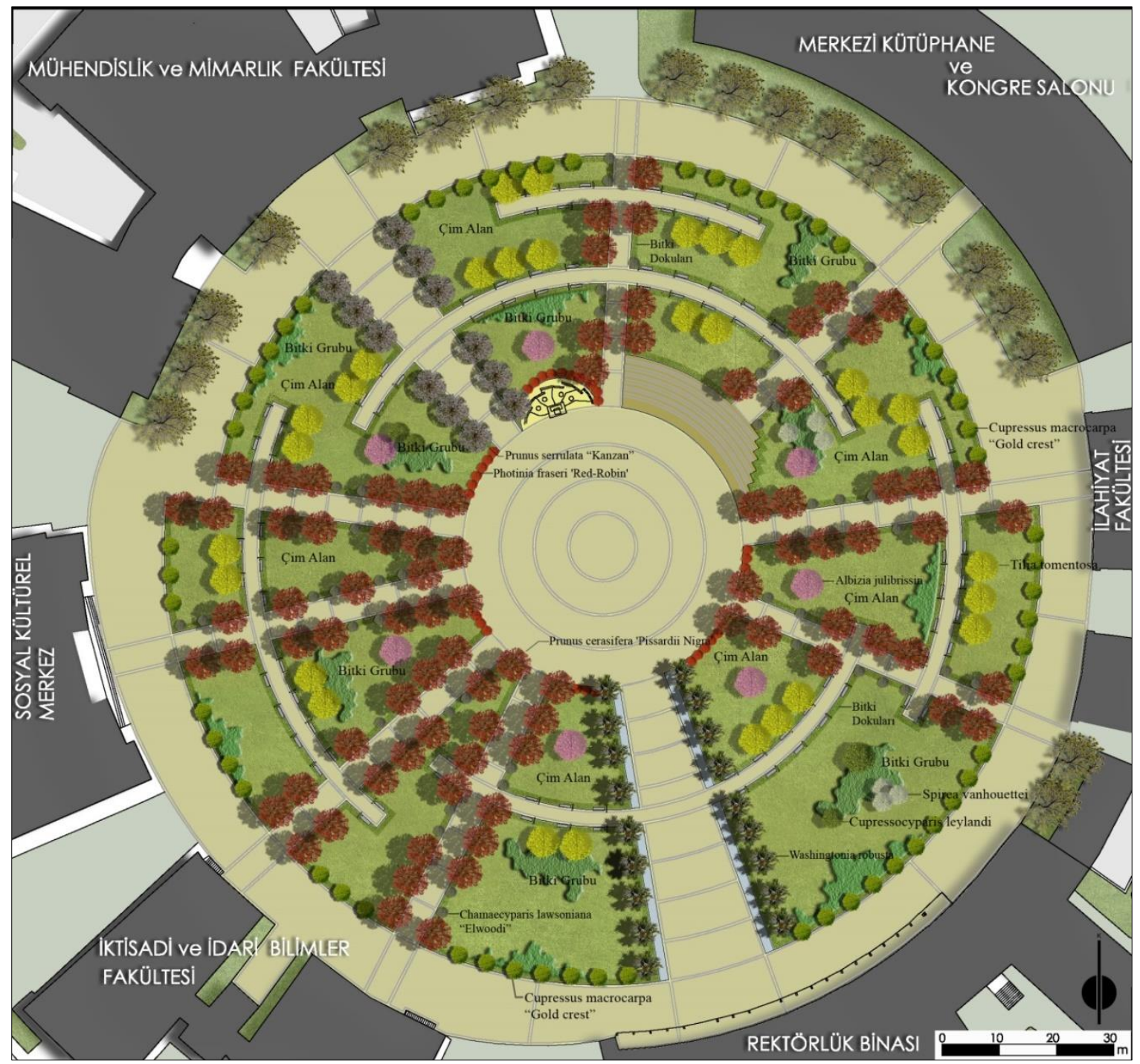

Şekil 10. Bitkisel peyzaj projesi

Çalılar: Agave americana (Sabır), Berberis thunbergii "Atropurpurea” (Kırmızı yapraklı kadın tuzluğu), Chaenomeles japonica (Bahar dalı), Euonymus japonicus (Taflan), Euonymus japonica “Auera” (Alacalı taflan), Gaura spp.(Gaura), Lantana camara (Çalı mine), Lantana montevidensis (Yayılıcı mine), Lavandula angustifolia (Lavanta), Ligustrum vulgare (Kurtbağr1), Rosmarinus officinalis (Biberiye), Spirea vanhouettei (Keçi sakalı), Santolina chamaecyparissus (Gri lavantin), Photinia fraseri “Red robin” (Alev çalıs1), Viburnum opulus (Yaprak döken kartopu).

Yerörtücü ve mevsimlikler: Ageratum houstonianum (Vapur duman1), Bellis perennis (Koyun gözü), 
Cerastium tomentosum (Fare kulağı), Calendula officinalis (Portakal nergisi), Chrysanthemum sp. (Kasımpatı), Dahlia (Yıldız çiçeği), Narcissus spp. (Nergis), Tulipa spp. (Lale), Petunia sp. (Petunya), Viola sp. (Menekşe) Sarılıcı bitkiler: Lonicera caprifolium (Hanımeli), Ampelopsis americana (Amerikan sarmaşığı), Hedera helix (Kaya sarmaşı̆̆ı).

Alana dikilen bitkiler, büyüme ve gelişmelerini sürdürebilmeleri için yeterli ve düzenli sulamaya ihtiyaç duymaktadır. Bu nedenle bitki türlerinin ihtiyacı doğrultusunda uygun sulama sistemi belirlenerek oluşturulan sulama ağı oldukça önemlidir. Bu doğrultuda geniş çim alanlarda spring sulama, çalı, ağaççık ve yerörtücü türler için ise damlama sulama tercih edilmiştir.

\subsection{Uygulama Aşaması}

Tasarım aşamasının sonlanmasından sonra Kilis 7 Aralık Üniversitesi Yapı İşleri ve Teknik Daire Başkanlığı tarafından ihale edilen proje yine aynı birim tarafından kontrol edilerek uygulanmıştır (Şekil 8). Alanda tesviye çalışmasının yapılmasının ardından elektrik, aydınlatma, havuz ve diğer inşaat faaliyetleri tamamlanmıştır. Daha sonra ise etkinlik alanı, oturma basamakları ve yürüyüş yolları için döşeme çalışması yapılmıştır (Şekil 11). Bunun yanında tasarım projesi doğrultusunda oturma birimleri ve bitki kasaları yürüyüş yolları üzerinde yer alacak şekilde yerleştirilmiştir. Tamamlanan yapısal çalışmalar sonunda bitkisel tasarım doğrultusunda bitkiler yerleştirilmiş ve dikim işlemi tamamlanmıştır. Alanın çim alan tesisi de gerçekleştirilerek, uygulama sonlandırılmıştır (Şekil 12).
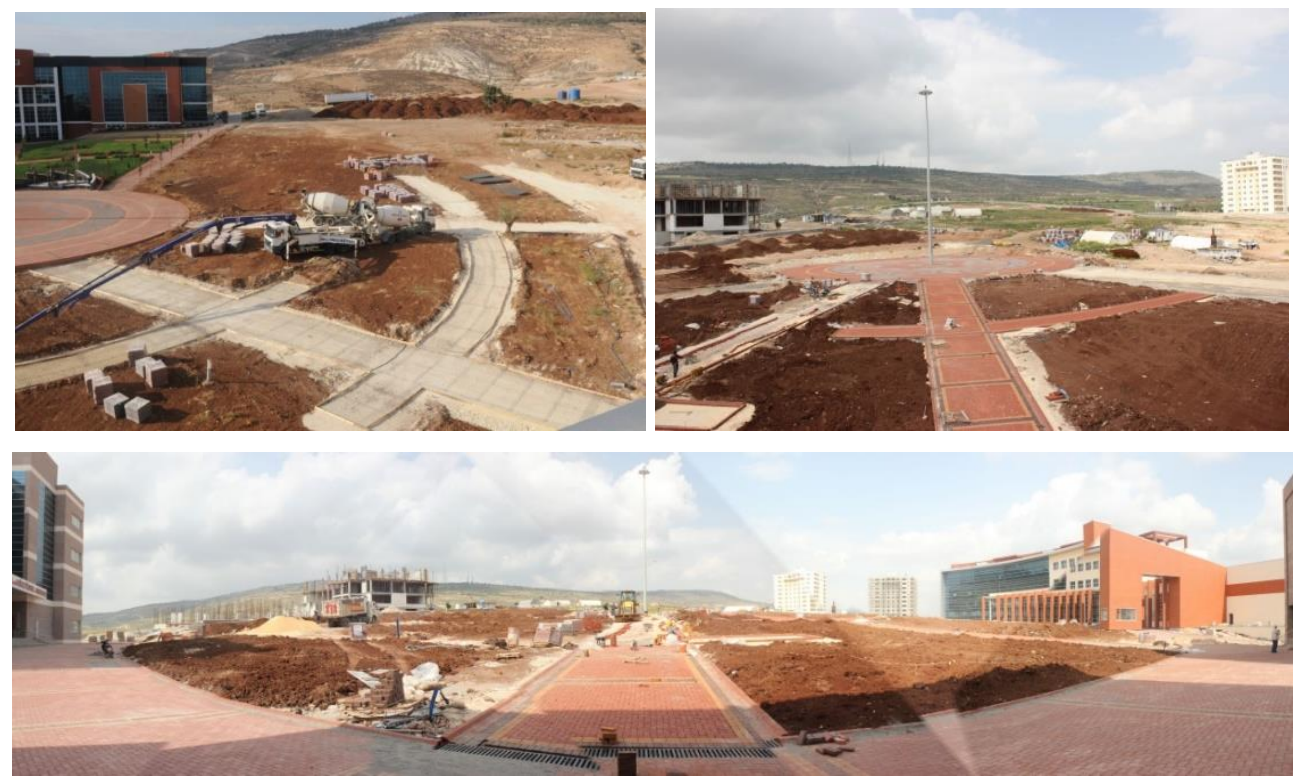

Şekil 11. Uygulama aşaması
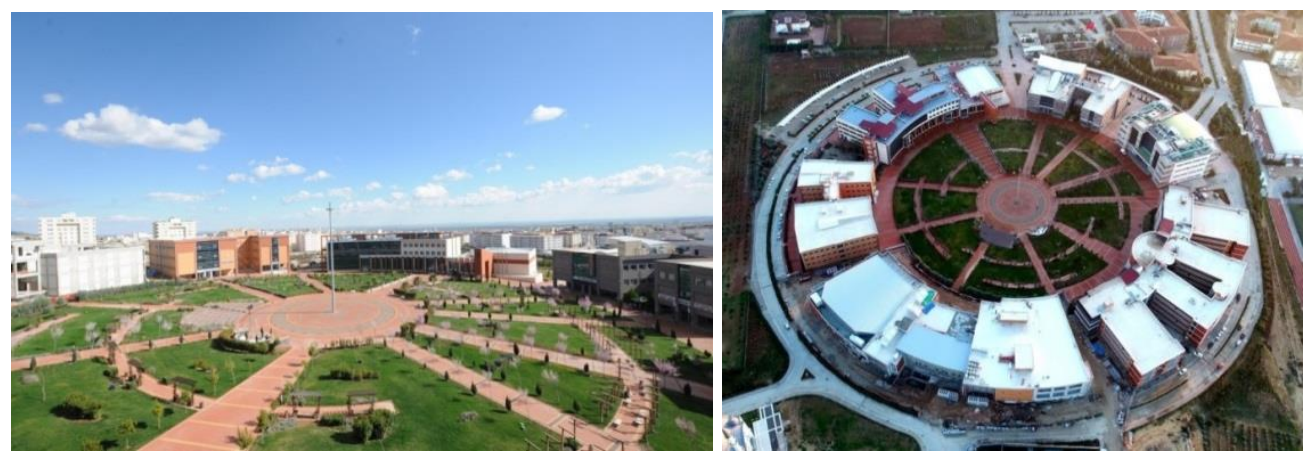

Şekil 12. Projenin tamamlanmış hali 


\section{Sonuç ve Öneriler}

Üniversite içerisinde yer alan açık yeşil alanların sosyal aktivitelere izin verecek fonksiyonda olmasının yanı sıra ders aralarında öğrencilerin dinlenmesine elverişli bir biçimde düzenlenmesi önemlidir. Şüphesiz doğa ile temas halinde olan bireyler daha verimli ve huzurlu bir ortamda bulunduklarını düşünmektedir. Gençler için tasarım süreci fiziksel ve doğal özelliklerinin engeller değil, tasarım firsatları olarak görülmesini içerir (Bredow, 2006). Bu bağlamda Kilis 7 Aralık Üniversitesi Kampüsü Meydan Tasarımı Projesi önemlidir.

Düzenli (2010) gençlerin sosyalleşme ve kişiselleşme ihtiyaçlarını karşılayabilmek için uygun etkinlikleri gerçekleştirmeye, bu etkinlikleri gerçekleştirmek için de hareketlilik, doğallık ve (etrafı seyretmeye uygun) açıklık olanaklarına sahip mekânlara ihtiyaç duyulduğunu ifade etmektedir. Bu bağlamda tasarım projesi;

- Kolay erişilebilir olmasının yanı sıra yapısal çevre ile uyumlu,

- Farklı aktiviteler içeren ve her dönem kullanıma uygun,

- Doğal çevreye ve iklimsel koşullara uyumlu, su isteği bakımından kanaatkâr türleri barındıran,

- Ders döneminde dinlenme, ders çalışma, sosyal etkinlik dönemlerinde eğlenme, akademik tören dönemlerinde toplanma işlevlerini içeren,

- Kampüs için bir çekim noktası oluşturacak etkinlik alanlarına sahip estetik ve işlevsel özelliklerin bir arada bulunduğu bir mekân kurgusu içerisinde yapılmaya çalışılmıştır.

Tasarım projesi 2011 yılı, projenin alana uygulanması 2013 yılı itibariyle tamamlanmıştır. Tasarım sonucunda etkinlik ve tören alanı, oturma alanları, amfi, süs havuzları tasarlanmış ve öğrenci ile personel kullanımına açılmıştır. Tasarımda sert zemin düzenlemesiyle alan olarak uyumlu bir yeşil alan kullanımına özen gösterilmiştir. Mekânın yapılar arasında yer alıyor olması kuşatılmışlık hissi verdiğinden dolayı olabildiğince yer örtücü ve çalı türleriyle görüş açısında genişlik ve rahatlık hissi oluşturulmaya çalışılmıştır.

Üniversiteye ait bir mekân olması sebebiyle örnek teşkil edebilecek uygulamaların yer almasına özen gösterilen çalışma, kullanıcılar açısından bir çekim noktası oluşturmayı hedeflemiştir. Gerek yapısal, gerek bitkisel tercihler bu doğrultuda yapılmıştır. Bu duruma örnek olarak Spirea vanhouettei (Keçi sakalı), (Lavanta), Rosmarinus officinalis (Biberiye), Santolina chamaecyparissus (Gri lavantin), Gaura spp, (Gaura), Pitosporum tobira"Nana"(Bodur pitos), Viburnum opulus (Herdemyeşil kartopu), Photinia fraseri (Alev çalısı), Chaenomeles japonica (Bahar dalı), Forsythia intermedia (Altın çanak) gibi türlerin kentte ilk defa bu alanda kullanılması ile birlikte, bu bitkilerin il genelinde yaygın bir biçimde kullanılır hale gelmesi verilebilir.

Tasarımın yapıldığı yıl olan 2011 'de 4425 öğrencisi bulunan üniversite günümüzde 8926 öğrenciye hizmet vermektedir. Bu süreç içerisinde üniversite 3 adet kampüse ayrılmış ve merkez kampüsteki öğrenci sayısı 4157 öğrenci iken 6700'e çıkmıştır. Ayrıca 2011 yılında 75 idari, 116 akademik personel bulunmakta iken, bu sayı günümüzde 205 İdari, 124 Sürekli işçi (Güvenlik, hizmetli) ve 368 akademik personel olarak değişmiş ve ortalama 7500 kişiye hizmet verir hale gelmiştir. Özellikle bahar şenlikleri döneminde sosyal aktiviteler ve konser gibi etkinliklerde bu sayının 13000'e kadar yükseldiği tespit edilmiştir. Bu anlamda değerlendirildiğinde başta üniversite olmak üzere yerel halkın kullanımına da izin verilen alan, barındırdığı etkinlik alanlarıyla tercih edilir duruma gelmiş ve amacına uygun bir gelişim göstermiştir.

Tüm bu bilgiler ışığında, çalışmada elde edilen bulgular, projenin oluşturulmasında izlenen yol, tasarım kararları gibi unsurlar ile ileride yapılacak olan kampüs tasarımı projelerine örnek teşkil edeceği ve öneriler sunacağı düşünülmektedir.

\section{Kaynaklar}

1. Alexander C (1977). A Pattern Language. New York: Oxfort University.

2. Altunkasa F (2011).Peyzaj Mühendisliği. Çukurova Üniversitesi Ziraat Fakültesi Yayını Geneel No:123. Ders Kitapları Yayın No: A-36, Adana.

3. Bredow KW (2006). Gathering Spaces: Designing places for adolescents, Faculty of the Virginia Polytechnic Institute and State University. Master of Landscape Architecture.

4. Düzenli T (2010). Kampüs Açık Mekan Olanaklarının Gençlerin Psikososyal Yapısına Bağlı Olarak İncelenmesi: K.T.Ü. Kanuni Kampüsü Örneği. Karadeniz Teknik Üniversitesi Fen Bilimleri Enstitüsü, Doktora Tezi.

5. Gür Ş Ö (1996). Mekan Örgütlenmesi. Gür Yayıncılık, 280 s, Trabzon. 
6. İnceoğlu M (2007). Kentsel Açık Mekânların Kalite Açısından Değerlendirilmesine Yönelik Bir Yaklaşım: İstanbul Meydanlarının İncelenmesi. Yıldız Teknik Üniversitesi, Fen Bilimleri Enstitüsü, Doktora Tezi, İstanbul.

7. Kamberov A (2016). Bir Kamusal Açık Alan Olarak Meydan Kullanımını Etkileyen Kararların Kullanıcılar Tarafından Değerlendirilmesi: Bakü Azadlık Meydanı Örneği İstanbul Aydın Üniversitesi, Fen Bilimleri Enstitüsü, Yüksek Lisans Tezi, İstanbul

8. Krier R (1979). Urban Space. New York: Rizzoli Intl Pubns.

9. Lau S S Y, Gou Z, Liu Y (2014).Healthy campus by open space design: Approaches and guidelines. Frontiers of Architectural Research, 3(4), pp. 452-467.

10. Moughtin C (2003). Urban Design: Street and Square. Oxford: Architectural Press.

11. Öksüz A M, Aydemir Ş, Aydemir S E, Beyazlı D Ş, Ökten N, Sancar C, Özyaba M, Türk Y A (2004). Kentsel Alanların Planlanması ve Tasarımı, 373-406 s, Trabzon.

12. Payne S (2009) Open space: people space J. Environmental. Psyschol. , 29 (4) (2009), sayfa 532 533.

13. Vitruvius (2005). Mimarlık Üzerine on Kitap. İstanbul: Şevki Vanlı Mimarlık Vakfı. 